\title{
Research on the "Cloud" Early-warning Mechanism of Public Emergencies
}

\author{
Zhu Xiaoning \\ School of Political Science and Public Administration \\ University of Electronic Science and Technology of China \\ Chengdu, P. R. China 611731 \\ 1334695148@qq.com
}

\author{
Li Shiyi \\ School of Political Science and Public Administration \\ University of Electronic Science and Technology of China \\ Chengdu, P. R. China, 611731 \\ 497945343@qq.com
}

\begin{abstract}
With the rapid development of cloud computing, cloud management, which is IT-oriented, offers us a new idea and new method in solving complicated management problems. This paper focuses on solving the problem of information shortage in early warning, mainly explains the application of cloud computing in the early-warning mechanism of public emergencies, including its technical framework and application process, and thus constructs "cloud" computing in the early-warning mechanism of public emergencies, which consists of early-warning monitoring system, early-warning consultation system, early-warning organization system and early-warning support system. The paper also aims to demonstrate the feasibility of this mechanism through explaining that the efficiency of early-warning mechanism of public emergencies can be improved with cloud computing in that it can clarify the relationship among the sub-systems of the early-warning mechanism of public emergencies.
\end{abstract} Cloud

Key words-Public emergency; Emergency management;

\section{I.INTRODUCTION}

China has been continuously plagued by various kinds of public emergencies, which seriously influenced its social and economic development. Thus, Chinese government has realized the importance and urgency of perfecting the warning mechanism of public emergencies. As to the emergency plan, the State Council issued National General Public Emergency Plan in 2006. As to early-warning system, China has established the leading organization which is the State Council-oriented, including administrative body, operation mechanism, regional body and the state emergency management system with expert groups in it. As to early-warning legal system, China has established a relatively integrated legal system including natural hazards, accidental disasters, public health events and public security incidents.

Although the Chinese government has made huge investment into manpower, material and financial resources, the result of early-warning is far from satisfaction due to the backwardness and imperfection of traditional early-warning methods. Therefore, it is emergent to innovate the early-warning mechanism of public emergencies. This paper focuses on solving the information shortage in early-warning, based on the advantage of "cloud" management and the construction of "cloud" computing in the early-warning mechanism of public emergencies, which involves early-warning monitoring system, early-warning consultation system, early-warning organization system and early-warning support system.

\section{PROBLEMS OF THE EARLY-WARNING MECHANISM OF PUBLIC EMERGENCIES}

Public emergency refers to the natural disasters, accidental disasters, public health events and social security events which happen suddenly and have caused or may cause serious social harms and measures have to be taken ${ }^{[1]}$. Its four grades are general, serious, quite serious, and very serious ${ }^{[2]}$. The early-warning of public emergencies refers to the action that public emergency management department makes analysis on the information and materials collected and then makes predictions on the crisis that might happen and raise the warning to the public so that the public can take timely countermeasures to reduce their losses ${ }^{[3]}$. The efficiency of early-warning depends on the effective screening, discriminating, analyzing and integrating of the information ${ }^{[4]}$. Since public emergency management in China is still not mature, it comes to the conclusion that the early-warning mechanism of public emergencies mainly has the following problems based on the actual investigation and analysis.

\section{A. Disunity of early-warning organization}

At present, China's early-warning mechanism of public emergencies is taking the mode of "single disaster type, single department, and single industry". Seemingly, it appears that each department is performing its own functions with expertise and efficiency. However, due to the fact that there is no unified management, different departments are likely to compete for achievements and put the blame to others. This is especially true in the public emergencies of compound type which involve many departments, and would definitely influence the efficiency of early-warning and responding, which lead to bigger losses in economy and personnel ${ }^{[5]}$. With the development of social economy, public emergencies of compound type would certainly become the dominant emergency and the occurrence of the emergencies would easily lead to "secondary crisis". Thus, the prevention and responding to the public emergencies involve the coordination and resource allocation of many departments. 


\section{B.Defective information system}

Warning information is the basis for administrators to make decisions. At present, many problems still exist in the crisis information management system in China. In terms of vertical information management, "bureaucratic hierarchy" is adopted, which means crisis information is collected through the layer-upon-layer report of the subordinates. Due to the factors including information asymmetry, adverse selection and moral hazards, etc., it is difficult for the central government to effectively supervise the work of the local government. For the benefit of itself, local government tends to be selective on the information, which would easily lead to the false management such as making false report, withholding report, failing to report or delay reporting. In terms of horizontal information management, the integration of crisis information of different departments is implemented through regulations, systems and agreements. However, presently, the local government of China is still competing with each other, and each department is doing their best to increase the amount of the national resources within their control, and their priority is to win benefits for themselves over other departments ${ }^{[6]}$. This would definitely lead to conflicts among different departments and cause the appearance of "information isolated island"[7].

\section{CONSTRUCTION OF THE “CLOUD” EARLY-WARNING MECHANISM OF PUBLIC EMERGENCIES}

\section{A. Proposal of the "cloud" early-warning mechanism of public emergencies}

The latest definition made by the Wikipedia on cloud computing in 2011 is that it is a compute mode based on the Internet, and through this channel, the shared software and hardware resources and information can be provided to computer and other equipment as needed ${ }^{[8]}$. The framework of cloud computing consists of an enormous computer cluster, which consists of many computing tasks resource pools. Furthermore, it allows each user to apply and receive the corresponding computing power, storage and all kinds of software services.

\section{B.Function module of the early-warning mechanism of public emergencies}

\section{1)Early-warning monitoring system}

(1) Information collecting subsystem, which mission is to collect information related to the sources and signs of the crisis, etc. (2) Information processing subsystem, which is to systemize, classify, identify and translate the collected information. (3) Decision-making subsystem, which mission is to determine whether to send out the emergency warning and decide on the grade of emergency warning according to the result of information processing subsystem and then send out orders for warning subsystem. (4) Warning subsystem, which mission is to send warning to the people who should respond to the crisis or the potential victims immediately when the signs of emergency appear according to the monitoring results, so that proper measures can be taken ${ }^{[9]}$. 2)Early-warning consultation system

Regular information exchange provides research reports related to the crisis and put forward suggestions and advice, etc. to deal with the crisis.

\section{3)Early-warning organization system}

The early-warning organization system of public emergencies, which consist of related government departments, scientific research institutions, the public, news media, social intermediary organizations, etc. give full play to the dominance of governmental authority and the active collaboration of the society. Specialized institutions have been set up with staff conducting long term analysis and research on emergency early-warning mechanism and then report in time; normalized and systematized monitoring and prevention system has been established; smooth information exchange and processing channel is constructed.

\section{4) Early-warning support system}

Government should set up special fund to prevent public crisis, and encourage non-governmental organizations, profit-making organizations to actively participate in the establishment of early-warning and material support system. The country should formulate relevant laws and regulations to clarify responsibilities, motivate rewards and punishments.

\section{C.Operational principle for the "cloud" early-warning} mechanism of public emergencies

Early-warning mechanism is an important mechanism to prevent the emergency management from entering into initialization phase. It includes early-warning monitoring system, early-warning consultation system, early-warning organization system and early-warning support system. Through cloud computing, the risk sources that may lead to the event are identified and the preliminary assessment of the risks can be conducted. After summarizing the collected information, the logically scattered information can be transformed into logically centralized information so that indexes and parameters for describing the event can be obtained. Furthermore, there will be a basic understanding to the occurrence, development and evolution of the event. Based on the information obtained, comprehensive judgment is conducted and the decision of whether or not to issue early-warning is made. In case that the information in the previous phase reach the level to issue early-warning, then the grade of the early-warning should be evaluated and then the result of early-warning should be send out to warn relevant departments to make preparations for the emergency.

D. Design of the "cloud" early-warning mechanism of public emergencies

\section{1)Technical framework of cloud computing \\ (a) Cloud infrastructure layer}

Cloud infrastructure layer includes the contents in the infrastructure layer in the standard cloud computing platform, which mainly consist of hardware infrastructure and software infrastructure. Hardware infrastructure consists of hardware such as server, storage devices, etc. Software infrastructure consists of middle ware such as operating system, database server, documentation server, etc. 


\section{(b) Cloud computing platform layer}

Cloud computing platform layer mainly includes multiple programming design and development environment, distributed storage management system of massive structured data, massive data distributed file system and other system management tools to implement cloud computing. With various platform management technology, massive servers can work together, which is quite convenient to conduct various service deployment and fulfillment so that system fault can be discovered and recovered immediately, which ensures that the reliable operation massive system can be realized through intelligent and automatic means.

(c) Business service layer

Business service layer includes data access service layer and data storage service layer. These layers adopt standard Web Services and are planned based on SOA framework and are included into SOA system to be managed, allocated and used, which includes service interfaces such as service register, service access, service search, etc ${ }^{[10]}$. External system issues emergency information through invocating the data collection Web Services interface for the early-warning mechanism of public emergencies. The result of early-warning can be shown through getting access to the analysis result Web Services interface for the early-warning mechanism of public emergencies.

\section{(d) Business application layer}

Business application layer consists of various business application systems, including those for realizing information collection, conducting comprehensive prediction analysis, and issuing predicated early-warning results. Early-warning system of public emergencies and cloud computing platform are closely connected through business service layer. Business application provides Coarse-Grained business function, which can be reflected into missions in the business process; service description provides the clearly and reasonably defined interface for the business service layer so that business process can be easily applied without the understanding of the details of business application and technology platform; the service registration of business service platform ensures that business process layer can dynamically locate and get access to the service needed if the occasion should arise.

\section{2) Application process of "cloud" early-warning mechanism}

The first phase: monitoring

Information monitoring system conducts data collection and sends the massive daily professional data to Emergency Command Center through business service layer. After receiving the reported data collected by the system, the Emergency Command Center will distribute the information to the special stations to dispose. The related personnel will verify and affirm the reported contents. Its risk monitoring and accessing system has the function to conduct research and judgment on the reported data and make analysis and judgment on various data. Once there is an abnormal condition, the analysis and its conclusion will be sent out through the result display platform of cloud computing.

The second phase: early warning

Specialized departments, different functional zones and related departments share the assignments based on their own duties. After confirming the early-warning information that may cause certain serious production safety accidental event, deployment should be made according to the pre-arranged planning made by themselves and notification should be given to the related organizations and departments for them to take actions so as to prevent the event from further developing. Meanwhile, the event should be reported to the Emergency Command Center and Emergency Management Office of Administration of Work Safety according to the grade, trend and seriousness of the production accident and corresponding early-warning suggestions should be put forward.

The third phase: responding to the disposal

After the early-warning information being sent out, the municipal emergency response office, emergency response center, special command department and related departments should response according to the early warning and enter into the corresponding emergency working condition and initiate corresponding pre-arranged planning of public emergency disposal in due time, and fulfill their corresponding duties.

The fourth phase: assessment and summarization

After the event being disposed, the decision-making leader and related experts should make assessment on the disposal, summarize gains and losses, make improvement on related process and then put it into the related business mechanism such as pre-warning, pre-arranged planning and knowledge base, decision support, linkage coordination, on-site commanding, etc. so as to further improve the efficiency of manner, method and process in handling similar production safety emergencies ${ }^{[11]}$.

\section{FEASIBILITY OF THE “CLOUD” EARLY-WARNING MECHANISM PUBLIC EMERGENCIES}

The concept of cloud computing has been widely accepted in the industry and the application of cloud computing is showing a trend of expanding. There have been many successful cases, such as the overseas Web Services provided by Amazon and the search service provided by Google. In the domestic market, there are some famous enterprises including Baidu and Tencent are also expanding their services with cloud computing. Many countries and their governments also put forward the "cloud priority" development strategy. For example, the American government has asked its government to initiate the integration of date center operations, which make it possible for the government to provide one-stop IT service environment for the public by purchasing the service product of government cloud. The "cloud" early-warning mechanism of public emergencies will definitely transform the manner for the collection and sharing of information.

\section{CONCLUSION}

Cloud computing provides a new channel for the development of early-warning mechanism of public emergencies. The virtualization technology and dynamic resource pool management mode provides a more rapid, secure and convenient computing service and data storage service for early-warning mechanism, and changes it into a operating process of interconnected mechanism from information integration to information sharing, which makes it possible the sustainable development of early-warning 
mechanism of public emergencies.

\section{ACKNOWLEDGEMENTS}

I would like to express my gratitude to all those who helped me during the writing of this thesis. I gratefully acknowledge the help of my supervisor,Mr Zhu, who has offered me valuable suggestions in the academic studies. In the preparation of the thesis he has spent much time reading through each draft and provided me with inspiring advice. Without his patient instruction, insightful criticism and expert guidance, the comp letion of this thesis would not have been possible.

\section{REFERENCES}

[1] Crisis Management Research Group, School of Public Administration of Tsinghua University. Investigation Report of Crisis Awareness in Chinese Urban Residents. China Public Security, 2006(06): 40 (in Chinese)

[2] Gianfranco Poggi. The State: Its Nature, Development and Prospects. Stanford: Stanford University Press, 1990: 30-31

[3] Gao Xiao-ping and Hou Li-yan. Crisis Management Methodology [J]. China's Administrative Management, 2005(5) (in Chinese)

[4] Guo Ji et al. The Emergency Management System Construction of Central and Municipal Governments [M]. Renmin University of China Press, 2005: 99 (in Chinese)

[5] Huang Yun-fan. Early-warning Study on Integrated Model of Information Grid [D]. Chengdu:University of Electronic Science and Technology of China, 2013(6) (in Chinese)

[6] Li Jin-hua. Grid Knowledge Management [D]. Hubei: Wuhan University, 2005(4) (in Chinese)

[7] Li Xi-chen. Study of the Warning Mechanism of Government Public Emergencies in China [J]. Oriental Enterprise Culture, 2012(4) (in Chinese)

[8] The Law of People's Republic of China on Response to Emergencies. Retrieved from http://baike.Baidu.com/view/1177495. htm, 2013-1-10 (in Chinese)

[9] Wikipedia. Cloud Computing. Retrieved from http://en.wikipedia.org/wiki/Cloud_computing, 2011 (in Chinese)

[10] Yao Guo-zhang. Countermeasures and Suggestions for Promoting the Construction of Public Emergency System in China [J]. Information Construction, 2005(12): 86 (in Chinese)

[11] Yuan He-jun. Public Emergency Grid Management [D]. Chengdu: University of Electronic Science and Technology of China, 2007(6) (in Chinese) 